\title{
Liturgiese identiteitsvorming as antwoord op die invloed van die verbruikerskultuur
}

\author{
B.J. de Klerk
}

Skool vir Kerkwetenskappe

Potchefstroomse Universiteit vir $\mathrm{CHO}$

POTCHEFSTROOM

E-pos: kwsbjdk@puknet.puk.ac.za

\begin{abstract}
The formation of liturgical identity in response to the influence of a consumer culture
\end{abstract}

Liturgy in South Africa is continually interacting with the Western cultural heritage on the one hand, and increasingly with African culture on the other hand. However, another powerful influence on the local liturgy springs from the so-called global consumer culture. A few characteristics of the latter are inter alia the following: The emphasis on what the "buyer", the worshipper and "potential" worshipper prefer; a show business attitude resulting in transforming members of the congregation into spectators rather than participants. Furthermore the emphasis is on the pursuit of effectiveness and the utilisation of technology to attain it and the focus is specifically on the needs of the individual and not on those of the community. The continual formation of liturgical identity is the answer to the mainly detrimental cultural processes currently manifesting themselves. The point of departure in forming a cultural identity implies an in-depth study of the liturgical guidelines indicated in the Old and the New Testament and the historical development of liturgy, especially in the second, sixteenth and twentieth centuries. The following aspects should, however, also be taken into consideration: the contemporary characteristics of the local indigenous culture, beauty of God, relationship between liturgy and culture, multi-cultural enrichment of liturgy, missionary aim and eschatological focus of liturgy. 


\section{Beleef ons 'n liturgiese identiteitskrisis?}

Die debatte wat vandag oor liturgiese kwessies gevoer word, word nie net in ivoortorings gevoer nie. Die kerklike publiek neem vrylik daaraan deel - selfs in die dagblaaie (vgl. die debat oor simbole - Beeld, 2000:6, 8 en 13 Maart). Die spanning in kerkgemeenskappe oor sogenaamde tradisionele en sogenaamde vrye liturgieë (vgl. Aune, 1988:38) het in sommige gemeentes gelei tot afsonderlike dienste. Lidmate kan 'n keuse uitoefen watter soort dienste hulle graag wil bywoon. In sommige kringe word die preekstoel se simboliese waarde hoog geskat en die verdwyning daarvan word aan die invloed van die verbruikers- en vermaaklikheidskultuur toegeskryf (Lathrop, 1996:86). Ander beskou die preekstoel as 'n struikelblok in die kommunikasieproses van die gemeente se samekoms (Louw, 2000:8). Dui hierdie simptome op 'n liturgiese identiteitskrisis?

Op die terrein van die liturgie in Suid-Afrika behoort ernstige aandag aan voortdurende identiteitsvorming gegee te word. Dit blyk uit die groeiende besef dat ' $n$ kultuur wat van Westerse herkoms is, soos die Afrikaanse kultuur, in 'n Afrikaland aan al hoe meer invloede blootgestel word. Verder is daar ernstige pogings om die Afrika-kultuur te laat herleef - die sogenaamde Afrika-renaissance (vgl. Wilson, 1990:57, 58). Tans is daar ook nog 'n soort globale wêreldkultuur (die sogenaamde verbruikerskultuur) wat 'n sterk invloed op die liturgiese uitgangspunte en gebruike uitoefen. In hierdie ondersoek word gepoog om vas te stel wat die kenmerke van hierdie globale verbruikerskultuur is, hoe hierdie kultuur die liturgie beïnvloed en wat die wisselwerking tussen kultuur en liturgie behoort te wees. Ten slotte sal aangedui word hoe die vorming van liturgiese identiteit 'n antwoord is op die kulturele prosesse wat tans aan die gang is.

\section{Kenmerke van die globale verbruikerskultuur}

Aram (1996:96) onderskei drie belangrike verskynsels in die moderne samelewing:

- Pluralisme het 'n wêreldverskynsel geword en dit bring nuwe vrese, hoop en uitdagings.

- Kultuur het, in sy interaksie met godsdiens en etnisiteit, 'n bron van sosiale, politiese, ekonomiese, godsdienstige en etniese verdeeldheid en spanning geword.

- Die Westerse samelewing se identiteit het aansienlik verander in 'n tegnologiese samelewing wat sekularisasie bevorder en 'n monokultuur vorm. Juis hierdie verspreiding van 'n nuwe monokultuur druk 
'n stempel op liturgiese handelinge af, wat ook die liturgie se identiteit ingrypend kan verander en degradeer.

\subsection{Verbruikerskarakter}

Die eerste en oorheersende kenmerk van hierdie globale monokultuur is sy verbruikerskarakter. Die adverteerder, wat moet sorg dat sy produk verkoop, vra nie meer na "wat is goed" van die produk nie, maar na "wat is verkeerd" met die koper. So verskuif die balans van produknavorsing na marknavorsing. Die liturgie wat hierdie mentaliteit oorneem, vra wat die verbruiker in die liturgie wil hê en hoeveel kopers hy kan trek, en nie soseer na die kwaliteit van die liturgie, naamlik of dit is wat God wil hê nie. Dan verander liturgie na pseudoterapie en is dit nie meer die genesende openbaring van God nie (Dawn, 1995:24). Die grootste gevaar van 'n bemarkingsaanslag in die liturgie is dat dit erediensdeelnemers soos verbruikers hanteer - miskien godsdienstige verbruikers, maar tog nog verbruikers. Die verbruikerskultuur, wat beheer word deur ekonomiese materialisme, verminder die waardeoordele tot 'n optelsom van koste en voordele. Weggesteekte ideologieë van die verbruikerskultuur is verpak in Pizza Huts, McDonalds, Coca-Cola, ensovoorts en bring waar dit oor die wêreld voorkom, nuwe kulturele norme, paradigmas en waardesisteme (Aram, 1996:97). Hierdie verbruikerskarakter van kultuur werk soos erosie in op die betekenis, beginsels en waardes van die Westerse kultuur (Mitchell, 1997:169). Verder moet inheemse kulture stoei om iets van hulle identiteit te verstaan deur hulle omgang met die evangelie, omdat die mensgeoriënteerde verbruikerskultuur die wêreld indring deur kommunikasie en tegnologie. Kulturele imperialisme is hier op sy sterkste aan die werk (vgl. Ross, 1995:61).

\subsection{Tegnologiese karakter}

Die meeste waarnemers van die huidige kultuur benadruk die ingrypende invloed wat tegnologie en tegnologiese denkwyses het op die laat twintigste-eeuse samelewing (White, 1993:176). Dit is wetenskaplik vasgestel dat 'n kind wat oormatig televisie kyk, 'n kleiner ontwikkelde brein het (Dawn, 1995:6). Die tegnologie het, om één voorbeeld te noem, die groot probleem van verlies aan intimiteit in persoonlike verhoudinge gebring. Die gebrek aan intimiteit in geloofsgemeenskap plaas vals druk op die liturgie om deur tegnieke intimiteit te produseer. Liturgie kan nie die lewe grondig verander as die tegnologiese karakter van die monokultuur nie getransformeer word in eiesoortige waardes, wat selfs kontra die kultuur kan wees nie. Deel van die tegnologiese denkwyse is die eensydige strewe na die één waarde, naamlik doeltreffendheid. Om doeltreffend te wees is spoed van belang en daarom word die diep eksegetiese grondslae in die liturgie in prediking uitgesny, minder verse 
gesing en die slegste van alles: stilte word vermy. Die musiek moet vinnig en vrolik wees en daar is min tyd vir klaagpsalms, skuldbelydenis en verootmoediging (Dawn, 1995:41). Die Nagmaal moet, byvoorbeeld, 'n soort fast food-karakter kry (wat te enige tyd op enige plek genuttig kan word) omdat die lewenswyse deur 'n soort fast food-kultuur geïnfekteer is (Bieritz, 1993:181).

\subsection{Verpolitisering}

Nog 'n kenmerk van die globale verbruikerskultuur is die verpolitisering daarvan. Die klem op die vryheid van die individu, selfbeskikking en persoonlike outonomie het - aan die een kant - van die liturgie 'n voertuig van protes gemaak en aan die ander kant - daartoe gelei dat die verantwoordelikheid vir die transformering van kultuur afgestaan is aan die politieke leiers (Mannion, 1988:114).

\subsection{Individualisering}

'n Ander belangrike kenmerk van die globale verbruikerskultuur is individualisering. Juis die invloed van die elektroniese media vervang die betrokkenheid by die publieke lewe, opvoeding en kuns met show business en vermaak. Die tegnologiese samelewing isoleer mense al meer van mekaar met die gevolg dat mense net fokus op eie behoeftes en nie meer op dié van die gemeenskap nie. Die klem val tans eensydig op individuele en subjektiewe dimensies van die Christelike geloof as 'n regstreekse ervaring van God. Verder swaai die gemeenskap met die God wat Homself openbaar oor na die God wat begryp kan word in die misterie van die selfomgang met God (Mannion, 1988:106). Liturgie verloor sodoende die krag om kultuur te transformeer, omdat dit die tendense van die globale verbruikerskultuur in homself opneem. Liturgie word sodoende eensydig ' $n$ soort van terapie en liturge bemeester die kuns om op 'n soort terapeutiese wyse op die individu se gemoed in te werk. Die leemte wat deur die onpersoonlike tegnologiese samelewing op die intieme vlak van die gemoed gelaat word, word nou kunsmatig deur sekere liturgiese benaderings gevul. Die mite wat oorgedra word, is dat die sosiale misstande deur demone van onpersoonlikheid, vervreemding en koudheid veroorsaak word. Daarom moet die liturgie nie op die openbare terrein werk en die samelewing en kultuur probeer verander nie, maar moet dit wel konsentreer op die private, persoonlike ervarings van intimiteit en verhoudinge. Daar word geredeneer dat die kleingroep die ideale ruimte is vir liturgiese handelinge, want 'n groot gemeente is onpersoonlik, bevorder vervreemding en belemmer intimiteit (Mannion, 1988:112, vgl. Hovda, 1991:73). 


\subsection{Ingesteldheid op vermaak}

Die argument om die verbruikerskarakter van die globale kultuur in die liturgie te gebruik, is dikwels om seekers friendly te wees. Daarom is evangelisasie dikwels op vermaak ingestel. Vermaakgeoriënteerde liturgieë, so word beweer (Kallestad, 1990:17), laat kerke groei en die kerke wat doen wat hulle altyd gedoen het, krimp. Maar vermaak gekombineer met individualisme en pragmatisme verloor die Bybelsgebaseerde riglyne vir die liturgie en die band met die historiese kerkgemeenskap se regulerende beginsels van die liturgie - riglyne wat deur die eeue gelouter en beproef is (Peters, 1994:168). In die ernstige poging om te evangeliseer word gesoek na programme wat mense sal interesseer. Ons dink ons moet heuning smeer aan die bitter beker van verlossing. Ons kry dikwels die verhaal van die bruilof te Kana in 'n ander vorm. Op die kritieke oomblik wat die wyn opraak, neem mense die oplossing van die probleem in eie hande en gebruik as 't ware die ses kanne om Kool-Aid te meng (Hart, 1995:459). Die verdunde en kunsmatige drank van die populêre kultuur moet nou die verfynde, ryk en geurige nuwe wyn van die evangelie vervang.

\section{Die verbruikerskultuur ontspoor die liturgie van sy historiese Iyn}

\subsection{Los van historiese lyn en eie kultuurerfenis}

Twee belangrike liturgiese bewegings oorheers die tweede deel van die twintigste eeu, naamlik die Liturgiese Beweging en die Charismatiese Beweging (vgl. Fenwick \& Spinks, 1995:4). Die Liturgiese Beweging sluit al die hoofstroomkerkgemeenskappe in. Die tipiese karaktertrekke van dié beweging is ' $n$ herontdekking van die plek van die Bybel in die liturgie, die herontdekking van die liturgie van die vroeë kerk en die tweede eeu as model vir liturgiese handelinge en deelname van die gemeente aan die liturgie. Verder ook 'n poging om tot eenheid te kom oor basiese liturgiese beginsels, 'n herontdekking van die krag van die Nagmaal, 'n herontdekking van ander Christelike tradisies en die beklemtoning van die eie taal en kultuur in die liturgie, asook die beklemtoning van sosiale betrokkenheid as vrug van liturgiese handelinge (Fenwick \& Spinks, 1995:5-11). Dié beweging probeer om die lyn met die historiese wortels van die liturgiese handelinge te behou, met die uitdruklike voorneme om die inheemse kulturele karakter daarvan te behou en te versterk.

Dit is noodsaaklik om die objektiewe waarheid van die evangelie in die liturgie oor te dra op 'n wyse wat verband hou met mense se daaglikse ervarings en hulle diepste emosies en bekommernisse (inkulturalisasie). 
Daarom is insig in die eie aard van kultuur noodsaaklik, want dit bring kennis van wat mense doen en waarom hulle dit doen, asook insig in hulle idees, waardes en diepste oortuigings (Fitzpatrick, 1987:37). Daar is redelik wye konsensus dat kultuur 'n gemeenskap se "ontwerp vir oorlewing" is, die somtotaal van die wyse van lewe wat deur 'n groep mense oor ' $n$ aantal geslagte ontwikkel is (Thom, 1998:64). Waar die inheemse kultuur deur 'n globale verbruikerskultuur bedreig word, moet dit 'n negatiewe invloed op die denkpatrone en waardes van die plaaslike kerkgemeenskap hê. Die verbruikerskultuur ontwortel die liturgie in dié sin dat die klem nie meer op die produk (die liturgiese beginsels en kwaliteit) geplaas word nie, maar op die resultate van eksperimente en die uiterlike sukses wat dié soort liturgie bring. Aan die ander kant bied inkulturasie die geleentheid aan die kerk en sy liturgie om tradisionele gegewenhede te heroorweeg. Dit hou selfs die moontlikheid in dat die teologie hierdeur tot 'n nuwe interpretasie van die kerk se roeping in die wêreld kan kom (Van der Merwe, 1997:1395).

\subsection{Die liturgiese standaarde verlaag}

Hoewel die liturgie wat fokus op die verbruiker 'n "vrye liturgie" (teenoor die sogenaamde "tradisionele liturgie") genoem word, is dit nie vry nie omdat dit ook 'n tradisionele stroom volg, naamlik die Charismatiese beweging. Hierdie koers word kritiekloos gevolg ten spyte van die skeurings wat dit veroorsaak het (Fenwick \& Spinks, 1995:111). Die reaksie op en aansluiting by die verbruikerskultuur bring mee dat intimiteit "geskep" word op baie verskillende wyses, asook die ervaring van God se teenwoordigheid. Die Charismatiese Beweging het die praize-and-worship-movement gevestig as een van die belangrikste handelinge in die liturgie en die kenmerk daarvan is uitbundige, eenvoudige, ritmiese liedere en die betrokkenheid van 'n span voorsangers en begeleiers (Brink, 1997:16). Dikwels is dit 'n herhaling van sekere gedeeltes, begelei deur standaardinstrumente van 'n rock band. Wat weggelaat word uit die liturgie, is die intrede (votum en seën), belydenis van skuld, belydenis van geloof, die Onse Vader-gebed en Skrifverklarende prediking. Die toeligting uit die Skrif wat in hierdie tipe liturgie gebruik word, is meer terapeuties as teologies (Hart, 1995:452). Hierdie wyse van liturgiebeoefening is die produk van ontwikkelings na 1960 in die Amerikaanse popkultuur, gekoppel aan evangeliserende motiewe. Die Bybelse beginsels en hoofmomente in die geskiedenis van die liturgie word losgelaat en liturgie word, soos kos en klere, bloot 'n kwessie van smaak en eksperimentering. Dié liturgie kan nie "vrye liturgie" genoem word nie, omdat dit net so "tradisioneel" en "formalisties" is as die sogenaamde konfessionele liturgie, omdat dit die vaste patroon van musikale struktuur en lirieke telkens herhaal, maar dan op informele 
wyse (Hart, 1995:455). Die skerpste kritiek teen die inkorporering van die verbruikerskultuur in die liturgie is dat die diens en elemente daarvan so ontwikkel is dat hulle die aandag trek, in plaas daarvan dat dit voertuie is om bewondering vir God uit te druk. Die gemeente moenie in 'n gehoor, verkondiging in 'n vertoning en liturgie in vermaak verander word nie (Webster, 1992:16).

Wanneer die Bybelse en historiese lyn van liturgie losgelaat word en sodoende die band met die kerk van alle eeue losgesny word, verlaag die standaarde van die ontmoeting tussen God en sy gemeente. Christene is in 1994 in hulle fondamente geskud toe 'n anti-aborsieprotesteerder 'n doktor en verpleegster vermoor het in sy poging "om lewens te spaar". Dalk is die analogie te blatant, maar is die verlaging van standaarde, op die lang termyn, nie net so fataal vir die geloof - as dit gedoen word "om siele te red" nie? As liturgie die Christelike geloof net voorstel as bestaande uit aangename gevoelens, waar sal die innerlike krag vandaan kom in tye van terminale siekte, onstabiliteit in die gesin of ander terugslae? As liturgie net pret is, hoe moet mense dan ander gelowiges help wat konflikte beleef? (Dawn, 1995:280). Die liturgie moet sterker kos (suiwer en opregte Woordverkondiging en aanbidding), soms slegte maar genesende medisyne (verootmoedigende skuldbelydenisse) en duiselendwekkende water (vrees en bewondering vir God se krag, liefde, oordeel en genade) voorsit aan lidmate en soekendes (Radner, 1988:702).

\section{Liturgie se wisselwerking met kultuur}

\subsection{Die noodsaak van balans}

Inkulturasie beteken dat die beginsels, historiese wortels, waarde en betekenis van die huidige liturgie beoordeel word. Dit moet gedoen word in die lig van die roeping om God se boodskap duidelik in 'n bepaalde plaaslike gemeenskap te kommunikeer. Die vereiste is dus om die liturgiese beginsels te ken, asook die wyse waarop die betekenis daarvan in die kulturele konteks van die gemeente oorgedra moet word (Felde, 1998:43). Die geskiedenis van die liturgie leer dat die Christelike liturgie, waarvan die oorsprong in die Ou Testament, en by Christus en sy apostels lê, geïntegreer is met die kulture van die Grieke en Romeine, die Franco-Germane en so deur die eeue met kulture in alle kontinente (Chupungco, 1996:78).

Die dinamiese wisselwerking tussen liturgie en kultuur behels vier belangrike balanse: die balans tussen outentiek én relevant; konfessioneel én katoliek (met 'n kleinletter); plaaslik én wêreldwyd; Christosentries én antroposentries (vgl. Stauffer, 1996:325). Eensydig 
outentiek bring mee dat liturgie kultureel irrelevant, dood, betekenisloos en ontneem van die krag van die Heilige Gees kan wees. Eensydig relevant beteken dat liturgie sinkretisties, geïsoleer van die kerk van Christus kan wees, ontwortel van sy Christelike karakter. Liturgie moet enersyds getrou die belydenis van 'n bepaalde kerkgemeenskap weerspieël, maar tegelyk die basiese ooreenkoms handhaaf met die belydenis van die kerk van alle eeue. Die besondere eienskappe van 'n plaaslike kultuur kan die liturgie verryk: die styl van kommunikasie, die inheemse liedere, die eie aard van die taalgebruik in gebede. Maar die balans moet wees dat die liturgie nie net die plaaslike konteks moet reflekteer nie, maar ook die wêreldwye Christelike gemeenskap: Skriflesings, verkondiging, gebede, Doop en Nagmaal. Enersyds moet die nood, vrese, hoop en verwagting van die mens betrek word, maar dit moet in balans gebring word met die feit dat Christus, die Gekruisigde en Opgestane, sentraal staan in die liturgie: Hy is die Middelaar wat saam met die Vader en die Heilige Gees aanbid moet word. Dit is die sin van die liturgie.

Die liturgie mag nie so "vreemd" wees dat dit nie kommunikeer met sy kulturele omgewing nie, maar tegelyk nie so "plaaslik-eietyds" dat dit die evangelie van sy transformerende krag ontneem nie. Vernuwing en verdieping in die liturgie moet vanuit sy historiese wortels plaasvind, sodat die vernuwing met die beginsels en geskiedenis daarvan gebalanseer kan word (Dawn, 1995:257). Daar moet dus 'n soort dialektiese spanning wees tussen die universele/onveranderlike en die plaaslike/veranderlike; tussen die begeerte om identiteit in liturgie en kultuur te behou en die behoefte aan die suiwering van kultuur en die reformasie van liturgie (Fitzpatrick, 1987:193). Jesus bid in Johannes 17:14-18 vir hierdie dialektiese spanning by gelowiges. Hy stuur hulle in die wêreld en bid dat hulle nie van die wêreld sal wees nie. Daarom moet die liturg wat van kulturele vorme, nuwes en oues, gebruik maak, nooit ophou om voortdurend seker te maak dat die kultuur in ooreenstemming is met die ewige wêreld waaraan hy nou behoort nie. En daarom moet die kerk as alternatiewe gemeenskap die verbruikerskultuur op sy kop omkeer en moet die liturgie hom verset teen die tendens om op eksperimentele wyse, los van beginsels, 'n verbruikersartikel te word om mense uit nuuskierigheid te lok (Dawn, 1995:260).

\subsection{Christus as die Transformeerder van kultuur}

Christus, as Hoof van die kerk, toon die rigting aan hoe die liturgie kultuur moet benader. Ten opsigte van Christus en kultuur is daar vier benaderings: Christus van kultuur; Christus teenoor kultuur; Christus bo kultuur; Christus en die transformasie van kultuur. Christus as Seun van God staan bo die kultuur, maar Hy het mens geword en dit bevestig die 
goedheid van God in sy skepping en sy verlossing van die mens as kultuurvormer (Christus van kultuur). God oordeel in Christus die wêreld en veroordeel die wêreld se sonde (Christus teen kultuur). Die belangrikste is Christus as die Transformeerder van kultuur, want die evangelie moet verkondig word in die wêreld, in geloof moet vergewing ontvang word en daarmee God se vryspraak. Die gevolg is nie die vernietiging van kultuur nie, maar die transformasie daarvan (Spinks, 1993:44). Jesus Christus, deur sy kerk in die liturgie, daag kultuur se basiese paradigma of wêreldbeskouing uit (bv. die verbruikerskultuur) en omdat dit ' $n$ konfrontasie met die sentrum van die betrokke kultuur is, vra dit eers 'n paradigmaverandering ('n nuwe visie van kultuur in die lig van die verlossing deur Christus), en dan verdere ingrypende transformasie daarvan. Christus as Transformeerder van kultuur is dan ook Vernuwer daarvan en die Eén wat nuwe lewe in kultuur inblaas (Thom, 1998:78).

Liturgie het die verantwoordelikheid om ook kontra-kultuur te wees. Wanneer die liturgie se styl dié van die markplek met sy vermaak word; wanneer sukses gemeet word aan vol parkeerplekke en die hoeveelheid mense wat getrek word, dan moet die kwaliteit, waarde, integriteit en beginsel van die liturgie dikwels daaronder ly. Die beswaar is nie teen eietydse liturgie nie, maar dat dit die heerlikheid en onbegryplike grootheid van God agter menslike vertonings wegsteek. Omdat liturgie inherent die hele gemeente se werk is ("volk se werk") en altyd deelname van elke lid van die kerkvolk vra, kan dit nie beplan word as verbruikersartikel of om te vermaak nie, al word dit gedoen in die naam van 'n seekers-friendly-evangelism (Stauffer, 1996:330). Die liturgie wat deur die verbruikerskultuur geïnfekteer is, het die neiging om van gespesialiseerde kunstenaars, gepoleerde aanbieders en professionele administratiewe strukture gebruik te maak en sodoende die deelname van die gemeente en besoekers te minimaliseer (Mitchell, 1991:366). Liturgie moet kultuur soms ondermyn, want liturgie gee nie bloot aan die oppervlakkige nood van die tyd aandag nie, maar spreek die nood wat diep lê aan, 'n nood waarvan die soekende persoon dalk nie eers weet nie. God-gerigte liturgie is vir die belangstellende ongelowige aanvanklik dalk soos 'n klap in die gesig (vgl. 1 Kor. 14:23-25). Maar dan ervaar hy sensitiwiteit. Wanneer liturgie outentiek is, sal die soekende se persoonlike waarneming skerper word, totdat hy sien wat hy tot op daardie oomblik gemis het: God is! God is hier. God is werklikheid, nie bloot 'n projeksie of 'n optimistiese ideologie of 'n uitvinding van mense se fantasieë nie. God is regtig hier! (Gaddy, 1992:42).

\section{Beginselvas, asook eietyds}

Die begrip worship (meestal die draagwydte van die Afrikaanse "liturgie") kom uit die Oud-Engelse weorth wat beteken eer en waardigheid 
(worthiness) en scipe wat beteken skep (create). Dit gaan om die wyses te ontdek om God te eer in 'n eietydse idioom in antwoord op sy magtige Woord en sy skeppingswerke (Dawn, 1995:76). Die regulerende beginsel (ordo) om dit te ontdek kom uit die Woord en is die duidelike voorskrifte aan elke liturgie op elke plek dwarsdeur die eeue. Hierdie regulerende beginsel laat vryheid aan elke plaaslike kerk op 'n bepaalde tyd om 'n gewetensoordeel te maak oor sake waarvoor daar nie ewige voorskrifte is nie. Die ordo is die vergadering van die gemeente, Skriflesings, verkondiging, voorbidding, die geniet van die Nagmaal, die Doop en die wegstuur van die gemeente vir sy missie in die wêreld (Aune, 1988:39; vgl. Lathrop, 1996:72; Brink, 1997:41-44). Nadat die ordo vasgestel is, moet materiaal vir die ordo op 'n positiewe wyse in die plaaslike kultuur gevind word, terwyl die plaaslike kultuur tegelyk krities ontleed word sodat tot kontra-kulturele aksie gekom kan word. Hierdie werk is die werk van die plaaslike kerk, in gesprek met ander kerke.

Juis deur hierdie ordo kan die liturgie eietyds wees. In 1 Korintiërs 14:40 gebruik Paulus binne die raamwerk van die liturgie die begrippe "welvoeglik" en "ordelik". "Welvoeglik" beteken om ander lede (veral die swakkeres) in ag te neem en "ordelik" weer om liturgies so te funksioneer dat elke lid in harmonie met ander 'n funksie vervul. Genoemde begrippe kom uit die gewone menslike en siviele wêreld en so hou Paulus die groep mense in die gemeente, wat net op "hemelse ervaringe" (spreek in tale) konsentreer, se voete plat op die aarde. Hy sê met die begrippe: wat is normaal, behoorlik, fatsoenlik en eietyds (De Klerk, 1987:75-77). Dié begrippe leer die erediensdeelnemer om nie uit sy eie tyd te probeer ontsnap nie; nie deur strakke reglementering en oordrewe tradisionalisme nie, maar ook nie deur die oordrewe gejag na buitengewone charismata na 'n hemel op aarde vooruit te gryp nie. Dit beteken ' $n$ kreatiewe spanning tussen Bybelse beginsels en die riglyne uit die geskiedenis aan die een kant en eietydse inagneming van die plaaslike kultuur aan die ander kant (Peters, 1994:169). Vanuit innerlike noodsaaklikheid moet die huidige tyd ryp word vir 'n liturgie wat beginselvas en eietyds is (Schilson, 1996:109).

Die motiewe waarom die liturgie 'n groter eietydse klem moet kry, behoort duidelik aangedui te word. As die motief bloot verandering ter wille van 'n kultuur van voortdurende verandering is, kan dit in 'n plaaslike gemeente en in die kerk van Christus net tot groter verdeeldheid lei. Eén geldige motief mag die groeiende besorgdheid wees dat daar ' $n$ groter wordende kloof ontstaan tussen die kulturele ervaring wat mense in die week beleef en die ervaring wat hulle Sondae in die eredienste beleef. ' $n$ Tweede motief is die besef dat as lidmate God nie heelhartig in die openbare erediens hoor en antwoord nie, hulle evangeliese getuienis daardeur negatief geraak sal word (Brink, 1995:2). 
Dat gemeentes die weg opgaan van twee of meer afsonderlike dienste bloot net vir die smake in die gemeente, help nie om 'n bevredigende antwoord op die verbruikerskultuur, naamlik die vorming van 'n liturgiese identiteit, te bekom nie.

\section{Die vorming van 'n liturgiese identiteit}

\subsection{God is die sentrum van die liturgie}

Daar is opregte besorgdheid oor die willekeurige eksperimentering met die liturgie deur van die verbruikerskultuur se metodes gebruik te maak, want dit is 'n akute fout om argeloos met die liturgiese identiteit van 'n gemeente en daarmee met die liturgie van die kerk van Christus wêreldwyd om te gaan. As 'n kerk of kerkgemeenskap identiteitsprobleme met sy liturgie het, kan metodes wat skynbaar op ander plekke sukses behaal het (deur mense te trek), nie bloot ingevoer word nie. Dit kan dalk 'n ruk lank mense se aandag trek en 'n groter deurvloei van besoekers meebring, maar dit bied nie 'n blywende oplossing nie. Burger (1999:53 e.v.) bring die begrip "identiteit" in verband met dié vraag: "Wie is ons?" Dit gaan oor die vraag na die kerk se diepste liturgiese wese en wortels, wie die kerk in die lig van sy skepping en geskiedenis is. Omdat die lewe van die kerk in die liturgie weerspieël word, gaan dit oor die vraag na die grond van die kerk se bestaan, na die diepste lojaliteite en diepste verbintenisse, oor die vraag na die hart van die liturgie en die deelnemer aan die liturgie. Die Christelike gemeenskap is 'n alternatiewe samelewing (Dawn, 1995:215) en daarom is sy liturgiese identiteit van belang vir die geloofwaardigheid van die kerk. As belangstellende ongelowiges sien dat die kerk in sy liturgie anders is as die vermaaklikheidswêreld, sal die "geheime van hulle harte aan die lig kom", sal hulle voor God gestel word, en erken dat God werklik in die samekoms teenwoordig is (vgl. 1 Kor. 14:24, 25).

In sy ontstaansgeskiedenis in Israel was die liturgie se identiteit gekenmerk deur die leef in die magtige teenwoordigheid van God. God neem die inisiatief om onder sy volk te verkeer en uit sy teenwoordigheid spruit die seëninge vir die volk, blyk hulle vrees en bewondering vir Hom en ontstaan hulle liturgiese handelinge van gebed, sang en offers. In die stuur van die Eén wat "in die boesem" van die Vader leef om onder sy volk te woon en in die koms van die Heilige Gees om in die hart van die kerk te woon, maak God liturgiese handelinge in sy teenwoordigheid moontlik. Die diepste identiteit van die liturgie is dat God die sentrum van die liturgie is (Dawn, 1995:71). Die verhouding van God met die gemeente as korpus en as afsonderlike lede van die liggaam, hulle verhouding met Hom in Christus deur die Heilige Gees en hulle onderlinge verhouding met mekaar bepaal die liturgiese identiteit van 'n 
gemeente. Wanneer ander faktore toegelaat word om hierdie sentrum te oorheers, byvoorbeeld die strewe om voortdurend aan te sluit by die nuutste ontwikkelings van die omringende kultuur, dan kom die identiteit in gedrang. Die beslissende vraag in die liturgiese identiteitsvorming is die volgende: Is die eredienste, ander samekomste van die gemeente, gesins- en persoonlike aanbiddingsgeleenthede, byeenkomste waarin al die deelnemers ervaar dat hulle in die magtige, ontsagwekkende, liefdevolle, vrymakende en inspirerende teenwoordigheid van God in Christus kom? (Burger, 1999:74). Wanneer 'n gemeente se liturgiese identiteit hierdeur bepaal word, is daar plek vir 'n verskeidenheid mense wat verskillende beklemtonings het ten opsigte van dit wat eietyds is.

\section{2 "We are how we worship"}

Vir die kerk is sy liturgiese handelinge die mees sigbare en openlike gebeure om met die God van die Bybel om te gaan en om duidelik te maak wat dit beteken om Christen in die wêreld te wees. Daarom toon ons ons identiteit in die manier waarop ons ons liturgie beoefen ("we are how we worship" - Jones, 1995:347). Die identiteitskrisis in die liturgie word veral veroorsaak deur die oorheersende invloed van die verbruikerskultuur (soos hierbo aangetoon), asook deur die "geheueverlies" van die lidmate. Die gereformeerde liturgie sien krag in die gekruisigde Jesus; die populêre kultuur sien krag in die wenner van 'n handelstransaksie. Die liturgie verkondig hoop vanuit die opstanding van Christus; die populêre kultuur sien hoop in a new-car showroom. Die hoofdoel van die liturgie was altyd om God te verheerlik. Nou is die omgekeerde skynbaar waar: die hoofdoel van God is om mense te verheerlik (Jones, 1995:349). Karaktervorming, identiteitsvorming word bepaal deur die sosiale etos van dit wat vir mense in die omgewing belangrik is. Vir die gelowige is die gemeenskaplike ontmoeting met God in die erediens die sentrale aktiwiteit waarmee hulle hulle identiteit in die wêreld voor God aandui.

In die ontmoeting met God is daar minstens vyf belangrike momente. Die eerste is om bewus te word van en te fokus op God se teenwoordigheid, die tweede om sy groot dade te onthou en Hom te bewonder. Dan om sy seëning, genade, vryspraak, beloftes te ontvang en die ontvangs daarvan met blydskap te vier. Vierdens om by God oor ons nood en gebrokenheid te kla en skuld te bely oor dit wat die diepste pyn in ons lewens veroorsaak. Laastens om ons opnuut konkreet aan God toe te wy en ons verbintenis met Hom te herbevestig (vgl. Burger, 1999:206-212). Wie hierop konsentreer - en nie bloot op die volgorde van handelinge nie - sal die liturgiese identiteit, naamlik dat God en sy verhouding met ons en ons verhouding met Hom sentraal is, verstaan en konkretiseer in die eietydse kultuur. Dit beteken voortdurende aandag aan die 
interpretasie van liturgiese beginsels en tradisies, aan die heersende kultuur en aan moontlikhede om God te midde van ons vrese en hoop te verheerlik (Aune, 1988:41).

\section{Enkele riglyne vir die vorming van 'n liturgiese identiteit}

- Die vertrekpunt behoort 'n vashou te wees aan die liturgiese grondlyne wat in die Ou en Nuwe Testament gegee word. Dit gaan om God se teenwoordigheid, sy inisiatief, sy verheerliking as sentrum van hierdie identiteit. In die grondlyne word basies twee lyne onderskei, naamlik die lyn van die sinagogale erediens met sy Woorddiens (Skriflesings, Skrifverklaring en toepassing) en die lyn van die Bovertrek met sy tafeldiens. Daarbenewens is die doop, volharding in gebede en liedere deel van dié grondlyn (Vos \& Pieterse, 1997:13).

- 'n Verdere riglyn is die nagaan van die ontwikkeling van die liturgie, met konsentrasie op die tweede, sestiende en twintigste eeue. Die tweede eeu was in 'n sekere sin nog die wittebrood van die kerk en daarom was die liturgiese identiteit nog nie baie besoedel met dwalinge in die kerk en kulturele uitwasse van buite die kerk nie. Die sestiende eeu bring grondige reformasie, 'n terugkeer na die Skrif en die liturgie van die tweede eeu. Die Liturgiese Beweging van die twintigste eeu en die Charismatiese Beweging, met sy uitwerking op die liturgie, is noodsaaklike studiemateriaal vir herbesinning oor liturgiese identiteit.

- Vir ware liturgiese identiteitsvorming is stilte nodig. Stilte is die geestelike ruimte waarin die mens se gees hom die beste kan voorberei op sy ontmoeting met God. Vir innige gemeenskap met God het die gelowige tyd nodig waarin hy bewus kan raak van God se teenwoordigheid en stil genoeg raak om Hom te hoor praat (Burger, 1999:206). Ons nader tot God in paradoks en so is Hy sowel Woord as Stilte, die Eén wat nie stilgemaak kan word nie, maar ook die Eén wat in stilte met sy kinders kommunikeer. Die Woord van God is nie soos 'n motor met sy drom-geluide oor die radio as dit verby jou beweeg nie, maar die Woord kom soos 'n wildsbok wat jy hoor, maar nie in die oggendmis dadelik kan sien nie. As jy stil en wakker genoeg is, sal jy die bok van naby in sy skoonheid sien (Dawn, 1995:266).

- Liturgiese identiteitsvorming sal rekening hou met wat mooi in die Skrif en in die eietydse kultuur is. Die Skrif is vol van die skoonheid van God. Die toenemende verval van die huidige wêreld maak dit nog meer noodsaaklik vir die liturgie om ons te herinner aan die skoonheid van God. Minder en minder mense geniet die skoonheid van God se skepping. Armoede lei tot stadsverwoesting en oorbevolking. 
Moderne kuns verander dikwels die mooi in iets met 'n gewelddadige tema. In die identiteitsvorming van die liturgie sal die besef van die teenwoordigheid van God in die harte van lidmate ware verootmoediging bring en die erkenning van innerlike sondige vuilheid. Tegelyk sal dit bewondering bring vir die skoonheid van vergiffenis en ware dankbaarheid dat God ons nooi om die hemelse skoonheid te geniet, waarvan ons in die liturgie nou reeds stukkies kan smaak (Dawn, 1995:249). Kuns in die liturgie (woorde, simbole, geboue) stimuleer ons ervaring van God se geheime, ons bewondering vir Hom en help ons om die gewyde te beleef. Sonder kuns in die identiteitsvorming van die liturgie is ons afgesny van dit wat dieper betekenis in die lewe het. Hierin spreek die argitektuur mee. Die liturgiese ruimte(s) moet sowel die universaliteit van die kerk as die besondere kultuursituasie verbeeld. Die gemeente het ' $n$ visuele gevoel nodig dat hulle tot die kerk van alle eeue behoort, maar ook 'n gevoel dat hulle aanbiddingsruimte gasvry en vriendelik teenoor hulle is, wat ook al hulle kultuur mag wees (Stauffer, 1990:78).

- Die Suid-Afrikaanse kultuurtoneel moet indringend ontleed word. Die Afrikaanse liturgie moet seker maak dat hy vry is van die globale verbruikerskultuur se slegte invloede. Aan die ander kant moet die liturgie rekening hou met sy Afrika-verbondenheid en oop wees vir verryking deur die tipiese Afrika-kultuur met sy verhalende kommunikasiestyl, sy liggaamlike ekspressie, eiesoortige musiek en deelname van elke lidmaat.

- Elke kultuur het sy eie identiteit en dit moet ernstig in oorweging geneem word; daarom is taal 'n belangrike faktor in die vorming van 'n liturgiese identiteit. Die betroubare vertolker van die liturgie moet in sy poging om die ekwivalente boodskap en aanbidding oor te dra, weet wat dit oorspronklik in die Bybelse tyd wou oordra (Chupungco, 1996: 82). En al is liturgie kuns, moet die gebruik van liturgiese taal so hanteer word dat dit enersyds respek vir die heerlike God oordra en andersyds moet dit regstreeks en doelgerig in die algemene taal van die erediensdeelnemers wees (Jasper, 1991:282; Wall, 1991:424).

- In die identiteitsvorming sal multikulturaliteit ernstig geneem moet word. Multikulturaliteit is nie meer ' $n$ randverskynsel nie, maar dit het in Suid-Afrika 'n (dié?) karaktertrek van die samelewing geword (Von Bruck, 1992:246). Dit is belangrik dat mense uit verskillende kultuurgroepe dialoog met mekaar voer met as uitgangspunt die regulerende beginsel (ordo) van die liturgie. Verder om in die kulturele invoering daarvan in 'n multikulturele gemeente nie te vra wie se kultuur is reg nie, maar die moontlikhede wat elke kultuur bied, op die tafel te plaas en in ootmoed te oorweeg (McGaughey, 1999:73). Elke kultuur moet 
begin met wat dit is en wat dit het en dan die beste van die kultuur vir oorweging voorlê vir die nuwe identiteit van die betrokke liturgiese gemeenskap (Brink, 1995:2, 3).

- Identiteitsvorming gaan gepaard met die ontleding van wat eietyds is. Waar die liturgie van die begin en middel twintigste eeu bloot inligting oor God oorgedra het en min persoonlike betrokkenheid by God gevra het; waar dit sterk strukture oor verskillende volgordes ontwikkel het en die individu net deel daarvan kon word deur eers in die strukture opgeneem te word, het dit in die tweede deel van die eeu grootliks verander. Liturgie gaan om deelname, wat nie soseer met inligtingoordrag bewerk word nie, maar deur die betrokkenheid van die mens in sy totaliteit: deur simbole vir die gewone dinge van die lewe, deur kleure, prente en interpersoonlike verhoudings. Terwyl aan die basiese beginsels van die liturgie vasgehou word, moet daar buigbaarheid wees om liturgiese handelinge in te rig ooreenkomstig die eise van tyd en plek (Meyers, 1993:173) 'n Opmerking na die liturgiese handeling van prediking wat hierdie eietydse tendens opsom, is: "Pastor, when you teach, I learn something; when you preach, I meet God!" (Brink, 1997:43).

- Daar moet in die identiteitsvorming altyd 'n strewe na liturgiese eenheid, koinonia en ekumenisiteit wees. Daarom moet dit Trinitaries wees, Bybels begrond, tegelyk die aksie van Christus as Dienskneg van sy kerk en 'n doksologiese aksie van die kerk in die krag van die Heilige Gees. Die plaaslike gemeente moet bewus bly daarvan dat die één, heilige, algemene kerk in hulle teenwoordig is. Daarom moet die liturgiese identiteit gekenmerk wees deur nederigheid en waarheid, want die vorming van hierdie identiteit kan nie plaasvind buite die eenheid van die kerk van Christus nie (Lathrop, 1995:40). Daar is dus duidelike grense waarbinne die identiteit gevorm kan word en hiervan is die eenheid van die kerk in Christus nie die geringste nie (Chupungco, 1995:56).

- In die vorming van 'n liturgiese identiteit moet daar altyd 'n missionêre klem geplaas word. Die kerk is God se sending in die wêreld en moet ongelowiges met sy wyse van liturgiese handelinge konfronteer met God se genade en oordeel (vgl. 1 Kor. 14:23-25). Ongeveer in 1990 alleen het twee-en-'n-half miljoen mense in Europa en Noord-Amerika opgehou om God in Christus te aanbid (Dawn, 1995:279). Daarom het kerkleiers probeer om, in navolging van die markplein, nuwe wyses te ontwikkel om soekers te trek (en daarmee 'n nuwe identiteit gevorm). Hierdie soekers se sensitiewe emosies is gevorm deur supermarkte en televisie, waar onmiddellike sensasie gevra word. Mense word getrek deur kerke met groot parkeerareas, aangrypende 
dramas en feitlik geen of min verbintenisse (Marty, 1993:3). Daarom beweeg mense maklik van een groep na die ander. Soekers moet met vaste kos gevoed word, hulle moet die volle raad van God hoor en nie mislei word met 'n Jesus-liturgie wat draai om die Verlosser-God, waarby God as Skepper en Heilige uitgeskakel is nie (Senn, 1997: 328). Liturgiese identiteitsvorming neem die evangeliserende roeping in ag en bou ' $n$ vriendelikheid as vrug van die Gees in sy identiteit in, maar nie met die prysgawe van sy ordo nie. Die beste wyse van kontak met soekers is om te identifiseer met hulle pyn en ellende. In die identiteitsvorming moet gepoog word om die erediens te reformeer tot die plek waar God se etos (God se ontferming) en die mens se patos ontmoet (Saliers, 1994:21).

- Ten slotte moet die identiteitsvorming 'n sterk eskatologiese fokus hê. Ware liturgie moet 'n deurlopende eskatologiese moment hê en moet iets van die eindtyd weerspieël waarin almal onder Christus verenig sal wees. Dan sal die liturgie hoop bring vir die gelowige in sy nood en vir die soekende in sy wanhoop.

\section{Gevolgtrekking}

Die liturgie in Suid-Afrika is voortdurend in wisselwerking met enersyds die Westerse kultuurerfenis en andersyds al meer met die Afrika-kultuur. Maar 'n ander sterk invloed op die plaaslike liturgie kom van die sogenaamde globale verbruikerskultuur. Enkele kenmerke van laasgenoemde is: die klem op wat die "koper" - die kerkganger en "potensiële" kerkganger - graag wil hê; die lidmate en besoekers wat toeskouers eerder as deelnemers is en die fokus op die behoeftes van die individu en nie op die nood van die gemeenskap nie. Voortdurende liturgiese identiteitsvorming is die antwoord op hierdie, meestal skadelike, kulturele prosesse wat tans aan die gang is. Die vertrekpunte in die identiteitsvorming impliseer onder andere die volgende: 'n diepgaande studie van die liturgiese grondlyne wat in die Ou en Nuwe Testament gegee word en die historiese ontwikkelingsgang van die liturgie - veral in die tweede, sestiende en twintigste eeu. Verder moet aspekte soos die volgende ook in berekening gebring word: die eietydse eienskappe van die plaaslik-inheemse kultuur, die skoonheid van God, die multikulturele verryking van die liturgie en die missionêre gerigtheid en eskatologiese fokus van die liturgie.

\section{Bibliografie}

ARAM, I. 1996. The incarnation of the Gospel in cultures: A missionary event. The Ecumenical Review, 48:96-105.

AUNE, M.B. 1988. The corporate and confessional character of worship: The common service debate. Word \& World, 8(1):32-41. 
BIERITZ, K-H. 1993. Eucharistie und Lebensstil. Liturgisches Jahrbuch, 43:163-181.

BRINK, E.R. 1995. Changing the way we worship. Reformed Worship, 37:2-3.

BRINK, E.R., ed. 1997. Authentic worship in a changing culture. Study Report CRC. Grand Rapids : CRC Publications.

BURGER, C. 1999. Gemeentes in die kragveld van die Gees. Oor die unieke identiteit, taak en bediening van die kerk van Christus. Stellenbosch : BUFTON.

CHUPUNGCO, A.J. 1995. Liturgical inculturation and the search for unity. (In Best, T.F. \& Heller, D., ed. So we believe, so we pray. Towards koinonia in worship. Geneva : WCC Publications. p. 55-64.)

CHUPUNGCO, A.J. 1996. Two methods of liturgical inculturation. (In Stauffer, A.S., ed. Christian worship: unity in cultural diversity. Geneva : The Lutheran World Federation. p. 77-94.)

DAWN, M.J. 1995. Reaching out without dumbling down. A theology of worship for the turn-of-the-century culture. Grand Rapids : Eerdmans.

DE KLERK, B.J. 1987. Die Heilige Gees en die verhouding Skriflesing, prediking en gebed in die erediens. Potchefstroom : PU vir CHO. (Th.D.-proefskrif.)

FELDE, M. 1998. Truly vernacular worship for the sake of the gospel. International Review of Mission, 87:39-47.

FENWICK, J.R.K. \& SPINKS, B.D. 1995. Worship in transition. The liturgical movement of the twentieth century. New York : Continuum.

FITZPATRICK, S.J. 1987. One church many cultures. The challenge of diversity. Kansas City : Sheed \& Ward.

GADDY, C.W. 1992. The gift of worship. Nashville : Broadman Press.

HART, D.G. 1995. Post-modern evangelical worship. Calvin Theological Journal, 30(2):451-459.

HOVDA, R.W. 1991. The amen corner: Individualists are incapable of worship. Worship, 65(1):69-74.

JASPER, D. 1991. Between literature and liturgy: A pragmatics of worship. Anglical Theological Review, 73(4):375-387.

JONES, P.H. 1995. We are how we worship: Corporate worship as a matrix for Christian identity formation. Worship, 69(4):346-360.

KALLESTAD, W.P. 1990. Entertainment evangelism. The Lutheran, 23:16-25.

LATHROP, G.W. 1995. Knowing something a little. On the role of the Lex Orandi in the search for Christian unity. (In Best, T.F. \& Heller, D., ed. So we believe, so we pray. Towards koinonia in worship. Geneva : WCC Publications. p. 16-26.)

LATHROP, G.W. 1996. The shape of the liturgy: A framework for contextualization. (In Stauffer, A.S., ed. Christian worship: Unity in cultural diversity. Geneva : The Lutheran World Federation. p. 67-76.)

LOUW, L. 2000. Paulus sê: "Vir die Jode het ek soos 'n Jood geword". Beeld: 21, Maart 8.

MANNION, M.F. 1988. Liturgy and the present crisis of culture. Worship, 62(2):98123.

MARTY, M.E. 1993. Build a parking lot, and people will come (and go). Context, 25(4):3-4.

McGAUGHEY, D.R. 1999. More than right. A theological contribution to a discussion of cultural pluralism. Journal of Theology for Southern Africa, 104:69-73.

MEYERS, R. 1993. Liturgy and society: Cultural influences on contemporary liturgical revision. (In Bradshaw, P. \& Spinks, B., ed. Liturgy in dialogue. London : SPCK. p. 154-175.)

MITCHELL, N.D. 1991. The amen corner. "Liturgy and culture". Worship, 65:363-368.

MITCHELL, N. 1997. The amen corner. "Culture wars". Worship, 71(2):168-178. 
PETERS, T. 1994. Worship wars. Dialog, 33:166-173.

RADNER, E. 1988. What's wrong with the new liturgies? The Christian Century, 105(23):699-702.

ROSS, K.R. 1995. Christian faith and national identity: The Malawi experience. Journal of Theology for Soutern-Africa, 93:51-62.

SALIERS, D.E. 1994. Worship as theology: Foretast of divine glory. Nashville : Abingdon Press.

SCHILSON, A. 1996. Das neue Religiöse und Gottesdienst. Liturgie vor einer neuen Herausforderung? Liturgisches Jahrbuch, 46:94-109.

SENN, F.C. 1997. What has become of the liturgical movement? Its origins, current situation and future prospects. Pro Ecclesia, 6(3):319-332.

STAUFFER, A.S. 1990. Inculturation and church architecture. Studia Liturgica, 20(2):70-80.

STAUFFER, A.S. 1996. Worship and culture: five theses. Studia Liturgica, 26(2):323332.

SPINKS, B. 1993. Liturgy and culture: Is modern Western liturgical revision a case of not seeing the wood for the trees? (In Bradshaw, P. \& Spinks, B., ed. Liturgy in dialogue. London : SPCK. p. 28-49.)

THOM, G. 1998. Christ the transformer of culture? Studia Historiae Ecclesiasticae, 24(2):64-79.

VAN DER MERWE, P.J. 1997. Inheemswording en inkulturasie: implikasies vir teologie en kerk. Hervormde Teologiese Studies, 53(4):1376-1398.

VON BRUCK, M. 1992. Religionswissenschaft und interkulturelle Theologie. Evangelische Theologie, 3:245-261.

VOS, C.J.A. \& PIETERSE, H.J.C. 1997. Hoe lieflik is u woning. Studies in Praktiese Teologie. Pretoria : Die RGN-Uitgewery.

WALL. J.N. 1991. History, culture, and the changing language of worship: The case of the books of Common Prayer. Anglical Theological Review, 73(4):403-429.

WEBSTER, D.D. 1992. Selling Jesus. Downers Grove, II. : InterVarsity Press.

WHITE, S. 1993. Liturgy and technology. (In Bradshaw, P. \& Spinks, B., ed. Liturgy in dialogue. London : SPCK. p.176-201.)

WILSON, H.S. 1990. Worship and culture. Reformed World, 41(2):57-62.

\section{Kernbegrippe:}

identiteitsvorming

liturgie: interaksie met Afrika-kultuur

liturgie: Westerse kulturele erfenis

liturgiese identiteit

verbruikerskultuur

\section{Key concepts:}

consumer culture

forming of identity

liturgical identity

liturgy: interaction with African culture

liturgy: heritage of Western culture 